\title{
Questes
}

vestes Revue pluridisciplinaire d'études médiévales

$7 \mid 2004$

Les tabous

\section{Turning the pages : Feuilleter des manuscrits en} ligne

\section{Andrea Martignoni}

\section{(2) OpenEdition \\ 12 Journals}

\section{Édition électronique}

URL : https://journals.openedition.org/questes/2820

DOI : 10.4000/questes. 2820

ISSN : 2109-9472

Éditeur

Les Amis de Questes

\section{Édition imprimée}

Date de publication : 15 juin 2004

Pagination : 67-68

ISSN : 2102-7188

\section{Référence électronique}

Andrea Martignoni, «Turning the pages : Feuilleter des manuscrits en ligne », Questes [En ligne], 7|

2004, mis en ligne le 15 janvier 2014, consulté le 23 août 2022. URL : http://journals.openedition.org/ questes/2820; DOI : https://doi.org/10.4000/questes.2820

Tous droits réservés 


\title{
Mythe et politique à la fin du Moyen Age
}

\author{
http://www2.unil.ch/fra/Mythe.htm
}

Signalons l'ouverture de l'ENEE-DATABASE: « Mythe et politique à la fin du Moyen Age ». Cette base de données est le résultat d'un projet de trois ans soutenu par le FNS. Elle fournit une excellente bibliographie commentée (régulièrement mise à jour) qui recense actuellement plus de cent études et articles. Elle aborde essentiellement la question de la réception d'Enée à la fin du Moyen Age mais présente aussi des ouvrages relatifs à la notion de mythe (voir Questes, décembre 2001) et son utilisation politique lors du passage du Moyen Age à la Renaissance. Cette base permet d'offrir aux chercheurs des références non seulement sur Enée mais aussi de façon plus large sur des ouvrages relatifs aux problématiques littéraires médiévales. Son utilisation est facilitée par un moteur de recherche qui invite le lecteur à regrouper, à l'aide des mots-clés, les travaux qui l'intéressent et de s'en faire une première idée. Saluons donc cette belle initiative qui permet d'avoir un accès rapide et simple à ces stimulantes données.

Nelly LABERE

\section{Turning the pages}

Feuilleter des manuscrits en ligne http://www.bl.uk/collections/treasures/digitisation3.html

Au mois d'avril 2004, sous l'initiative de la British Library de Londres, s'ouvrent les portes d'une bibliothèque virtuelle de manuscrits. Basé au départ sur les fonds de la bibliothèque londonienne, ce projet vise à constituer un fonds de manuscrits provenant d'autres institutions européennes et mondiales, privées et publiques. Le concept est simple, mais les résultats sont surprenants, grâce à une technologie de pointe et à la digitalisation d'images de haute définition. On pénètre dans cette bibliothèque virtuelle; on choisit le manuscrit qui nous intéresse; enfin on n'a qu'à tourner doucement ses pages pour s'éblouir d'émotion. Parfois il est même possible d'agrandir des zones du texte ou des images. 
On ne peut que saluer cette initiative à la fois précieuse et perturbante. D'un simple clic de souris, on accède de près à des époustouflants bijoux du patrimoine livresque de l'humanité. Un voyage dans le temps, dans les couleurs, dans les formes et dans les textes accompli dans l'immobilité propre à l'internaute.

Pour le moment les manuscrits accessibles sur le site sont les suivants :

- cahiers de Leonardo da Vinci : le codex Arundel ms 263

- Le livre d'Heures des Sforza

- Psautier de Luttrell

- Évangile de Lindisfarne du VIIe siècle

- Haggadah dorée du XIV siècle

- Traité d'Anatomie de Vésale, $X V I^{\mathrm{e}}$ siècle

- Diamond Sutra : rouleau bouddhiste chinois imprimé en 868

- Missel de Sherborne, XV ${ }^{\mathrm{e}}$ siècle

- Sultan Baybars' Qur'an : magnifique exemplaire de calligraphie arabe

Andrea MARTIGNONI 